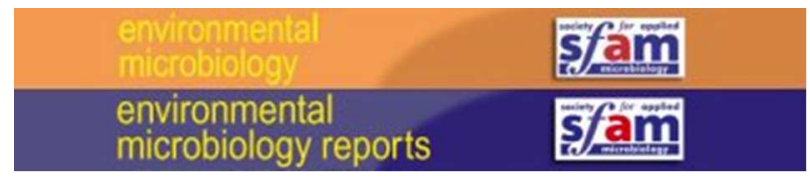

\title{
Cellulose production is coupled to sensing of the pyrimidine biosynthetic pathway via c-di-GMP production by the DgcQ protein of Escherichia coli.
}

\begin{tabular}{|r|l|}
\hline Journal: & Environmental Microbiology and Environmental Microbiology Reports \\
\hline Manuscript ID & EMI-2017-1046.R1 \\
\hline Manuscript Type: & Environmental Microbiology \\
\hline Date Submitted by the Author: & 18-Aug-2017 \\
\hline Complete List of Authors: & $\begin{array}{l}\text { Rossi, Elio } \\
\text { Motta, Sara; CNR, ITB } \\
\text { Aliverti, Alessandro; University of Milan, Biosciences } \\
\text { Cossu, Federica; University of Milan, Biosciences } \\
\text { Gourlay, Louise; University of Milan, Biosciences } \\
\text { Mauri, Pierluigi; CNR, ITB } \\
\text { Landini, Paolo; University of Milan, Biosciences }\end{array}$ \\
\hline Keywords: & $\begin{array}{l}\text { pyrimidine de novo biosynthesis, salvage pathway, c-di-GMP, diguanylate } \\
\text { cyclase, cellulose, signal transduction, environmental signal/stress } \\
\text { responses }\end{array}$ \\
\hline
\end{tabular}

\section{SCHOLARONE ${ }^{\mathrm{m}}$ \\ Manuscripts}


1 Cellulose production is coupled to sensing of the pyrimidine biosynthetic pathway via c-

2 di-GMP production by the DgcQ protein of Escherichia coli.

3

4 Elio Rossi ${ }^{1, \$}$, Sara Motta $^{2}$, Alessandro Aliverti ${ }^{1}$, Federica Cossu ${ }^{1}$, Louise Gourlay ${ }^{1}$, Pierluigi

5 Mauri $^{2}$ and Paolo Landini ${ }^{1 *}$

6

$7 \quad{ }^{1}$ Department of Biosciences

8 Università degli Studi di Milano

9 Milan, Italy

$10 \quad 2$ Institute of Biomedical Technologies

11 National Research Council,

12 Segrate, Milan, Italy

$13 *$ ) corresponding author:

14 Tel. +39-02-50315028

15 paolo.landini@unimi.it

16

17 \$) present address:

18 Elio Rossi: Department of Clinical Microbiology, Rigshospitalet, Copenhagen, Denmark

19

20 Running title: Cellulose production control by pyrimidines

21 Keywords: pyrimidine de novo biosynthesis, salvage pathway, c-di-GMP, diguanylate 22 cyclase, cellulose, signal transduction, environmental signal/stress response 


\section{Originality-Significance Statement}

2

3 How bacteria sense and react to specific signals has deep implications for their interaction

4 with their environment. In Escherichia coli, cellulose production (a stress response

5 mechanism in this bacterium) is coupled to the pyrimidine salvage pathway, in turn activated

6 by the availability of exogenous pyrimidines (e.g., uracil), via a signal transduction pathway

7 involving the second messenger c-di-GMP. The main sensor is the diguanylate cyclase DgcQ,

8 which is inhibited by N-carbmoyl aspartate, while being activated by UTP. This provides an

9 elegant mechanism to monitor which pathway the cell is using to make UTP, and to respond

10 accordingly. Since uracil positively affects the innate immune response, we speculate that the

11 connection between uracil sensing and cellulose production might have developed as a

12 preemptive defense mechanism against the host immune systems. 


\section{Abstract}

2

3 Production of cellulose, a stress response-mediated process in enterobacteria, is 4 modulated in Escherichia coli by the activity of the two pyrimidine nucleotide biosynthetic 5 pathways, namely, the de novo biosynthetic pathway, and the salvage pathway, which relies 6 on the environmental availability of pyrimidine nitrogenous bases. We had previously 7 reported that prevalence of the salvage over the de novo pathway triggers cellulose production 8 via synthesis of the second messenger c-di-GMP by the DgcQ (YedQ) diguanylate cyclase. In 9 this work, we show that DgcQ enzymatic activity is enhanced by UTP, whilst being inhibited by $\mathrm{N}$-carbamoyl-aspartate, an intermediate of the de novo pathway. Thus, direct allosteric

11 control by these ligands allows full DgcQ activity exclusively in cells actively synthesizing 12 pyrimidine nucleotides via the salvage pathway. Inhibition of DgcQ activity by N-carbamoyl13 aspartate appears to be favored by protein-protein interaction between DgcQ and PyrB, a 14 subunit of aspartate transcarbamylase, which synthesizes N-carbamoyl-aspartate. Our results 15 suggest that availability of pyrimidine bases might be sensed, somehow paradoxically, as an 16 environmental stress by E. coli. We hypothesize that this link might have evolved since stress events, leading to extensive DNA/RNA degradation or lysis of neighbouring cells, can result in increased pyrimidine concentrations and activation of the salvage pathway. 


\section{Introduction}

3

4 In the majority of bacteria, even the most basic cellular processes are directed by

5 environmental conditions: for instance, the main regulatory mechanism of DNA replication is

6 mediated by sensing of intracellular ATP concentrations (Skarstad and Katayama, 2013),

7 which is in turn a function of the energy sources available in the growth milieu. Similarly,

8 organic compounds, such as sugars or amino acids, can act as signal molecules to regulate the

9 expression of the genes involved in their own metabolism, in systems often known as 10 paradigmatic examples of gene regulation, such as the lactose operon (Miller, 1980).

11 Interestingly, however, in addition to regulating their own metabolic genes, organic molecules

12 often control the expression of genes involved in seemingly unrelated functions: for instance,

13 glucose availability in the $\mathrm{g} / \mathrm{L}$ concentration range regulates production of virulence factors in

14 several pathogenic bacteria (Fleming and Camilli, 2016; Eisenreich and Heuner, 2016; Wu et

15 al., 2016; Rossi et al., 2016), due to the fact that glucose at such concentrations can almost

16 exclusively be found in environmental niches associated with a host. Likewise, several other

17 environmental conditions, for example temperature or iron availability, not only control the

18 regulation of genes required to deal with the specific stress, but also impact genes involved in

19 adaptation to the host and/or of virulence factors through various forms of transcriptional and

20 post-transcriptional regulation (Falconi et al., 1998; Vasil and Ochsner, 1999; Llamas et al.,

21 2014; Righetti et al., 2016; Gu et al., 2016).

22 In motile bacteria such as Escherichia coli, one of the most important adaptation 23 responses to environmental signals is the switch between planktonic mode, characterized by 24 flagellar motility, and sessile (biofilm) mode. Flagellar expression and activity negatively 25 correlate with production of extracellular polysaccharides (EPS), thus promoting a switch 
1 from motile/planktonic cells to sessile cell aggregates, in a process directed by the bacterial

2 second messenger c-di-GMP (Simm et al., 2004; Hickman and Harwood, 2008; Boehm et al., 3 2010; Irie et al., 2012; Purcell and Tamayo, 2016). Intracellular c-di-GMP levels are 4 determined by the activity of diguanylate cyclases (DGCs), which synthesize the signal 5 molecule, and c-di-GMP phosphodiesterases (PDEs) that degrade it. Genes encoding proteins 6 involved in c-di-GMP turnover can be present in high numbers, especially in the genomes of 7 Gram negative bacteria (Römling et al., 2005); although a precise function has been assigned 8 to only a minority of c-di-GMP turnover genes, many of them appear to be involved in the 9 switch between planktonic and sessile lifestyle, with a variety of different mechanisms and in response to various environmental signals (Römling et al., 2013).

In a previous report (Garavaglia et al., 2012), we provided genetic evidence that

12 production of curli and cellulose, two main determinants for cell aggregation in E. coli, is 13 linked to the pyrimidine biosynthetic pathway. Cellulose production is activated in the 14 presence of exogenous uracil and inhibited by $\mathrm{N}$-carbamoyl-aspartate, an intermediate of the 15 de novo pyrimidine biosynthesis pathway, in a manner dependent on the DgcQ (formerly 16 YedQ) diguanylate cyclase. In this work, we show that the DgcQ protein can bind both UTP 17 and N-carbamoyl-aspartate, which affect its DGC activity in opposite fashions. Direct sensing 18 of these two molecules by DgcQ provides an elegant mechanism for coupling cellulose 19 production to the availability of exogenous pyrimidines and to the activity of the salvage 20 pyrimidine biosynthetic pathway, likely perceived as a stress condition by the bacterial cell. 21 We discuss the possible evolutionary significance of this regulatory mechanism. 


\section{Results}

2

3 Cellulose production is affected by exogenous uracil and by mutations in the de novo 4 pyrimidine biosynthetic pathway in a $\operatorname{dgc} Q$-dependent manner. Cellulose is produced by

5 many enterobacteria, including E. coli, mostly as a defense mechanism against environmental

6 stresses, such as nutrient starvation or desiccation (White et al., 2006; Gualdi et al., 2008).

7 Consistently, production of cellulose, and of other extracellular factors such as curli fibers,

8 typically takes place at suboptimal growth temperatures $\left(30^{\circ} \mathrm{C}\right.$ or lower, (Zogaj et al., 2001)).

9 However, this can vary in different E. coli isolates; for example, fecal isolates constitutively 10 produce cellulose at both $30^{\circ} \mathrm{C}$ and $37^{\circ} \mathrm{C}$, while UTI isolates preferentially synthetize 11 cellulose at $37^{\circ} \mathrm{C}$ (Bokranz et al., 2005). The E. coli laboratory strain MG1655 produces very 12 small amounts of cellulose, and exclusively at $30^{\circ} \mathrm{C}$ or lower; such low level cellulose 13 production is due to the presence of a stop codon in the $b c s Q$ gene in some $\mathrm{K}-12$ strains, 14 which results in reduced expression of the genes encoding cellulose synthase (Serra et al., 15 2013). However, overexpression of the AdrA diguanylate cyclase, a positive regulator of 16 cellulose synthase activity (Zogaj et al., 2001) or of CsgD, an activator of $a d r A$ transcription, 17 can overcome the effects of the $b c s Q$ mutations, enhancing cellulose production (Gualdi et $18 a l ., 2008)$. In a previous work, we showed that, when grown in the presence of an excess of 19 exogenous uracil (0.25 mM), MG1655 mutants impaired in either the carB or the pyrB genes, 20 which encode proteins involved in the first two steps of the de novo pyrimidine biosynthetic 21 pathway (summarized in Figure 1A), display a white mucous phenotype on media 22 supplemented with Congo red and are fluorescent in the presence of Calcofluor (Garavaglia et 23 al., 2012), two dyes able to binding various extracellular structures. As shown in Figure 1, 24 phenotypes on Congo red (CR)- and Calcofluor (CF)-supplemented media correlate with 25 cellulose production (Figure 1D) and are totally abolished by deletion of the bcsA gene, 
1 encoding the major subunit of cellulose synthase (Figure 1B, 1C), thus indicating that they are

2 dependent on cellulose production. Albeit at a much lower extent, exogenous uracil promotes

3 cellulose synthesis also in the MG1655 wild type, as well as in mutants in the downstream

4 steps of de novo pathway, such as pyrC ((Garavaglia et al., 2012); Figure 1). Interestingly,

5 addition of $0.25 \mathrm{mM}$ uracil, but not adenine, to LB1/4 medium supplemented with Calcofluor

6 strongly enhanced fluorescence in LF82, an adhering-invasive E. coli (AIEC) strain,

7 suggesting that induction of cellulose production by exogenous uracil is indeed a bona fide

8 regulatory mechanism in E. coli strains other than MG1655 (Figure 1C).

9 These observations suggest that uracil-dependent stimulation of cellulose production is

10 strongly enhanced in strains unable to synthesize N-carbamoyl-aspartate, regardless whether

11 they are unable to synthesize carbamoyl-phosphate (carB mutant) or if they accumulate this

12 intermediate ( $p y r B$ mutant). In E. coli, the cellulose biosynthetic machinery responds to c-di-

13 GMP, and more specifically to the activity of two distinct DGCs, DgcC (formerly known as

14 YaiC or AdrA; (Zogaj et al., 2001; Monteiro et al., 2009)) and DgcQ (YedQ), which appears

15 to play a particularly important role in cellulose regulation in the commensal E. coli strain

161094 (Da Re and Ghigo, 2006). DgcQ, but not DgcC, is required for induction of cellulose by

17 exogenous uracil ((Garavaglia et al., 2012), Figure 1), suggesting a specific link between

18 DgcQ activity and pyrimidine biosynthesis.

19 Identification of DgcQ interactors by co-purification experiments. Expression levels of

20 the $d g c Q$ gene were not affected by addition of $0.25 \mathrm{mM}$ uracil to the growth medium (Figure

21 S1A) indicating that exogenous uracil might affect DgcQ activity, rather than regulate its

22 expression. Thus, we sought for possible uracil-sensing regulatory proteins that might interact

23 with DgcQ, using pull-down experiments. To this aim, we expressed the DgcQ cytoplasmatic

24 domain, corresponding to the amino acid residues $381-564$, located immediately at the C-

25 terminus of the second transmembrane domain $\left(\mathrm{DgcQ}_{\mathrm{cyt}}\right.$, Figure $\left.2 \mathrm{~A}\right)$. The $\mathrm{DgcQ}_{\mathrm{cyt}}$ domain, 
1 linked to a histidine tag, was expressed and purified using a cobalt affinity column. The

2 overexpressed $\mathrm{DgcQ}_{\mathrm{cyt}}$ domain was found in the soluble fraction of the cell extracts only upon

3 expression at $18{ }^{\circ} \mathrm{C}$ (see Materials and Methods), remained soluble throughout purification

4 and could be fully recovered by imidazole elution. However, after purification, it precipitated

5 in aqueous solutions after ca. 48 hours regardless of the storage conditions (data not shown).

6 Despite lack of stability after imidazole elution, $\mathrm{DgcQ}_{\mathrm{cyt}}$ remained soluble when bound to the

7 column matrix as it could be eluted in a soluble form with $500 \mathrm{mM}$ imidazole even after

8 prolonged incubation (data not shown). The column-bound $\mathrm{DgcQ}_{\mathrm{cyt}}$ protein was used as a

9 "bait" to capture DgcQ interactors from cell extracts of E. coli MG1655 grown in LB1/4

10 medium either with or without $0.25 \mathrm{mM}$ uracil supplementation. Proteins binding to $\mathrm{Dgc} \mathrm{Q}_{\mathrm{cyt}}$

11 were recovered by elution of the histidine-tagged $\mathrm{DgcQ}_{\mathrm{cyt}}$ protein from the column with 250

$12 \mathrm{mM}$ imidazole, and identified by mass spectrometry, using Multidimensional Protein

13 Identification Technology (MudPIT; (Mauri, 2005)).

14 A full overview of MudPIT identification analysis is provided in the Supplementary

15 Information File S1. Interestingly, the pattern of cellular proteins interacting with $\mathrm{DgcQ}_{\mathrm{cyt}}$

16 changed significantly when we used cell extracts from E. coli grown either with or without

$170.25 \mathrm{mM}$ uracil. As shown in Table 1, several proteins were found to co-purify with $\mathrm{DgcQ}_{\mathrm{cyt}}$

18 in a manner strictly dependent on the growth conditions. In extracts of E. coli cells grown in

19 the absence of supplemented uracil, the main $\mathrm{DgcQ}_{\mathrm{cyt}}$ interactors appeared to be the Dcm

20 DNA methyltransferase, the putative phospholipid transporter MlaC, and the PyrB and PyrI

21 proteins (Table 1). The latter two proteins constitute the two subunits of aspartate

22 carbamoyltransferase, i.e., the enzyme catalyzing the synthesis of N-carbamoyl-aspartate from

23 aspartate and carbamoyl-phosphate (Figure 1A). This observation would suggest that the

24 apparent inhibitory activity of N-carbamoyl-aspartate on DgcQ-dependent cellulose

25 production (Figure 1B; (Garavaglia et al., 2012)) might be mediated by direct protein-protein 
1 interaction between $\mathrm{DgcQ}_{\mathrm{cyt}}$ and aspartate carbamoyltransferase. In contrast, neither PyrB nor

2 PyrI were detected among the $\mathrm{DgcQ}_{\mathrm{cyt}}$-interacting proteins found in extracts of cells grown in

3 the presence of $0.25 \mathrm{mM}$ uracil (Table 1): this could be expected, as UTP synthesized from

4 exogenous uracil via salvage pathway in turn negatively controls protein activity and

5 expression of several genes in the de novo pathway, including the pyrBI operon, through

6 complex feedback mechanisms (Turnbough and Switzer, 2008). We verified that uracil

7 supplementation in the medium would indeed result in downregulation of $p y r B$ expression in

8 the strain under the conditions we used. We observed that pyrB expression was strongly

9 dependent on growth phase in our experimental conditions, being higher in mid-exponential

10 phase (Figure S1B). When LB1/4 medium was supplemented with $0.25 \mathrm{mM}$ uracil, we

11 detected a 14-fold reduction in $p y r B$ transcript levels in mid-exponential phase (Figure S1B),

12 suggesting that lack of $\mathrm{DgcQ}_{\mathrm{cyt}}$-PyrBI interaction in cell extracts from MG1655 grown in

13 uracil-supplemented medium (Table 1) is due to low intracellular PyrBI concentrations

14 resulting from downregulation of $p y r B I$ expression.

15 In extracts from cells grown under this condition, the main $\mathrm{DgcQ}_{\mathrm{cyt}}$ interactors were 16 proteins involved in post-transcriptional tRNA modifications, namely, TruD (a pseudouridine 17 synthase) and TrmA (a 54-uridine methyltransferase), and the IF-1 initiation factor of protein 18 synthesis (Table 1). These results might suggest a possible role of DgcQ in important cell 19 processes other than cellulose production, such as tRNA processing and protein synthesis. 20 However, although the possible interaction between DgcQ with these proteins is intriguing, 21 we decided to concentrate our attention on the validation of DgcQ interaction with the 22 PyrB $•$ PyrI aspartate carbamoyltransferase, whose biological significance, in the light of our 23 genetic data ((Garavaglia et al., 2012); Figure 1), appears more straightforward.

24 Confirmation of DgcQ and PyrB•PyrI interaction by bacterial two hybrid system

25 (BACTH). In order to validate the results of the co-purification experiments, we verified 
1 protein-protein interaction between $\mathrm{DgcQ}_{\mathrm{cyt}}$ and either PyrB or PyrI, using the bacterial two

2 hybrid system (BACTH). The BACTH system relies on the expression of target proteins

3 fused with Bordetella pertussis adenylate cyclase subunits T18 and T25 in the E. coli

4 BTH101 strain. Upon positive interaction between two fusion proteins activity of adenylate

5 cyclase is reconstituted leading to transcriptional activation of the LacZ reporter (Karimova et

6 al., 1998). As shown in Figure 2B and 2C, $\mathrm{DgcQ}_{\mathrm{cyt}}$ showed strong protein-protein interaction

7 with $\mathrm{PyrB}$, i.e., the catalytic subunit of aspartate carbamoyltransferase, but not with PyrI,

8 whose function is to regulate PyrB activity. Likewise, no interaction was detectable between

$9 \mathrm{DgcQ}_{\mathrm{cyt}}$ and the PyrC protein, which catalyzes dihydroorotate formation using N-carbamoyl-

10 aspartate as a substrate. Although the BACTH assay can only provide a semiquantitative

11 measurement of protein-protein interaction, co-expression of $\mathrm{DgcQ}_{\mathrm{cyt}}$ and $\mathrm{PyrB}$ resulted in

12 CyaA activity levels in the same order of magnitude as PyrB-PyrI, which were used as a

13 positive control in our experiment (Figure 2B and 2C), suggesting strong interaction between

14 the two proteins.

15 As $\mathrm{DgcQ}_{\text {cyt }}$ interacts with PyrB, the catalytic subunit of aspartate carbamoyltransferase, but

16 not with the regulatory subunit PyrI, we asked ourselves whether PyrB-mediated N-

17 carbamoyl-aspartate synthesis would somehow be necessary for this interaction: thus, we

18 performed BACTH assays in both $\triangle c a r B$ and $\triangle p y r B$ isogenic mutants of the E. coli BTH101

19 strain, unable to synthesize carbamoyl-phosphate, in turn a substrate for the aspartate

20 carbamoyltransferase $\mathrm{PyrB}$, and $\mathrm{N}$-carbamoyl-aspartate itself, respectively (Figure 1A).

$21 \mathrm{DgcQ}_{\mathrm{cyt}}-\mathrm{PyrB}$ interaction appears unaffected in the $\triangle p y r B$ mutant strain, as determined by

22 CyaA activity levels (Figure 2B and 2C); however, the T25-PyrB fusion is fully functional

23 and complements the loss of the $p y r B$ chromosomal gene (data not shown), thus allowing N-

24 carbamoyl-aspartate synthesis and restoring a wild type-like phenotype. In contrast, in the

$25 \triangle \operatorname{car} B$ genetic background, co-expression of $\mathrm{DgcQ}_{\mathrm{cyt}}$ and PyrB failed to induce any detectable 
1 CyaA activity, strongly suggesting that lack of enzymatic activity by PyrB, due to the absence

2 of its substrate carbamoyl-phosphate, impairs its interaction with $\mathrm{DgcQ}_{\text {cyt }}$ (Figure $2 \mathrm{~B}$ and $2 \mathrm{C}$ ).

3 Finally, we used BACTH assays to investigate whether, in addition to downregulation

4 of the de novo biosynthetic genes by exogenous uracil, it might be possible that an increased

5 UTP availability via the salvage pathway might directly affect DgcQ-PyrB interaction. To

6 assess this possibility, we performed BACTH assays, using the T18-DgcQ ${ }_{\text {cyt }}$ and the T25-

7 PyrB plasmids, in the presence of $0.25 \mathrm{mM}$ exogenous uracil: no significant changes in

$8 \mathrm{DgcQ}_{\mathrm{cyt}}-\mathrm{PyrB}$ interaction were detected, suggesting that, despite downregulation of the de

9 novo pathway by exogenous uracil, PyrB is still enzymatically active in these conditions and

10 can fully interact with $\operatorname{DgcQ}_{\text {cyt }}$.

11 Interaction of DgcQ $_{\text {cyt }}$ with small ligands in vitro. The observations that cellulose

12 production is stimulated in mutants unable to produce $\mathrm{N}$-carbamoyl-aspartate, and that

$13 \mathrm{DgcQ}_{\mathrm{cyt}}$ interacts directly with $\mathrm{PyrB}$ in a manner dependent on its carbamoyltransferase

14 activity (Figure 2B and 2C) might suggest that $\mathrm{N}$-carbamoyl-aspartate might itself be a ligand

15 for $\mathrm{DgcQ}$ and as such promote $\mathrm{DgcQ}_{\mathrm{cyt}} \mathrm{PyrB}$ interaction. To assess protein-ligand

16 interactions, we performed a thermal denaturation temperature shift assay (Figure 3), which

17 relies on the stabilization of a protein (or domain) structure by ligand binding, in turn

18 resulting in higher denaturation temperatures (Cossu et al., 2010). In addition to N-

19 carbamoyl-aspartate, we tested the possibility that uracil, which, when provided to growth

20 media, also seems to affect DgcQ activity in vivo (Figure 1B) and its ability to interact with

21 other proteins (Table 1), might also be a ligand for this protein. GTP, as the known substrate

22 of DGC proteins, was used as a positive control in thermal denaturation temperature shift

23 assays, and indeed it resulted in an increase in $\mathrm{DgcQ}_{\mathrm{cyt}}$ denaturation temperature ranging

24 between 1.4 and $3.6^{\circ} \mathrm{C}$. Interestingly, the highest temperature shift was observed at the lowest

25 GTP concentration tested $(0.25 \mathrm{mM})$. This phenomenon might depend on different 
1 conformations assumed by $\mathrm{DgcQ}_{\mathrm{cyt}}$ upon binding on either one or more GTP molecules and

2 on initial conversion of 2 GTP molecules to c-di-GMP, with consequent allosteric product

3 inhibition, as already observed for other DGC enzymes (Schirmer, 2016). N-carbamoyl-

4 aspartate also induced a significant change (up to $3.9^{\circ} \mathrm{C}$ ) in $\mathrm{DgcQ}_{\text {cyt }}$ denaturation temperature,

5 although at higher concentrations than GTP $(2.5-5 \mathrm{mM})$. Uracil, in contrast, failed to show

6 any detectable change in the denaturation kinetics at any concentration used (Figure 3).

7 However, we reasoned that, once taken up by the bacterial cell, uracil is converted to UTP via

8 the pyrimidine salvage pathway (Figure 1). When tested in thermal denaturation temperature

9 shift assays, UTP, at a concentration as low as $0.25 \mathrm{mM}$, induced a slight shift in $\mathrm{DgcQ}_{\mathrm{cyt}}$

10 denaturation temperature $\left(1.1-1.3^{\circ} \mathrm{C}\right.$, Figure 3$)$, that is, to a lower extent than GTP or N-

11 carbamoyl-aspartate, and below the $3{ }^{\circ} \mathrm{C}$ threshold considered significant for these assays

12 (Cossu et al., 2010). However, neither ATP (Figure 3) nor CTP (data not shown) induced any

13 detectable change in $\mathrm{DgcQ}_{\mathrm{cyt}}$ denaturation temperature, suggesting that UTP-induced

14 temperature shift, albeit small, might indeed be due to a conformational change in $\mathrm{DgcQ}$ cyt

15 upon UTP binding. Thermal stabilization of the DgcQ cytoplasmic domain indicates that

16 DgcQ might directly bind N-carbamoyl-aspartate and, possibly, UTP suggesting that its

17 activity might be also influenced by either ligand.

18 UTP and N-carbamoyl-aspartate affect DgcQ $_{\text {cyt }}$ activity in opposite ways. As thermal

19 denaturation temperature shift assays suggest that both UTP and N-carbamoyl-aspartate can

20 bind the $\mathrm{DgcQ}_{\mathrm{cyt}}$ protein, we assessed their effect on $\mathrm{DgcQ}_{\mathrm{cyt}}$ catalytic activity in a 21 diguanylate cyclase assay. c-di-GMP formation was monitored by HPLC, as described in 22 Materials and Methods. Despite its poor stability, DgcQ ${ }_{\text {cyt }}$ retained its DGC activity, showing 23 an enzymatic activity level of $41.5 \mathrm{nmol} \mathrm{c-di-GMP} \min ^{-1} \mathrm{mg}^{-1}$, i.e., similar to what previously 24 reported for other DGCs, such as WspR and PleD (De et al., 2009; Antoniani et al., 2013).

25 However, reduced stability within 48 hours precluded replicating experiments on the same 
$1 \mathrm{DgcQ}_{\mathrm{cyt}}$ purification batch. Attempts to express different $\mathrm{DgcQ}_{\mathrm{cyt}}$ constructs in order to

2 improve long term stability were unsuccessful, as deletion of even few amino acids after

3 residue 381, although greatly improving protein stability, resulted in complete loss of its

4 enzymatic activity (data not shown). Despite these difficulties, we were able to assess the

5 effects of UTP and N-carbamoyl-aspartate on $\mathrm{DgcQ}_{\mathrm{cyt}}$ enzymatic activity on at least three

6 independent fresh purifications. In the presence of $2.5 \mathrm{mM} \mathrm{N}$-carbamoyl-aspartate, activity

7 was reduced by more than 10 -fold, consistent with direct binding of $\mathrm{N}$-carbamoyl-aspartate to

$8 \operatorname{DgcQ}_{\text {cyt }}$ suggested by thermal denaturation experiments (Figure 3), and with its inhibitory

9 effects on DgcQ activity in vivo (Figure 1). In contrast, UTP, already at $0.1 \mathrm{mM}$, resulted in a

10 2.5-fold increase in $\mathrm{DgcQ}_{\text {cyt }}$ activity; higher UTP concentrations (up to $2.5 \mathrm{mM}$ ) did not lead

11 to further stimulation (data not shown). Consistent with thermal denaturation assays shown in

12 Figure 3, ATP at concentrations up to $2.5 \mathrm{mM}$ did not significantly affect $\mathrm{DgcQ}_{\text {cyt }}$ activity

13 (data not shown).

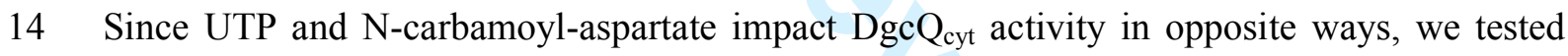
15 the possible dominance of either ligand: however, the results showed very high variability, 16 suggesting that the contemporary presence of UTP and N-carbamoyl-aspartate might further 17 destabilize the $\mathrm{DgcQ}_{\mathrm{cyt}}$ protein in our assay conditions.

\section{Discussion}

In this report, we have shown that allosteric control of DgcQ activity by both UTP (positive effector) and $\mathrm{N}$-carbamoyl-aspartate (negative effector) allows coupling of cellulose production to the pyrimidine salvage pathway in E. coli. When pyrimidine nucleotides are synthesized via the de novo pathway, of which $\mathrm{N}$-carbamoyl-aspartate is an intermediate, c- 
1 di-GMP synthesis by DgcQ and, consequently, cellulose production, are inhibited. On the

2 contrary, when the salvage pathway is active, leading to UTP synthesis from uracil and

3 consequent repression of the de novo pathway, DgcQ activity and cellulose production are

4 fully activated. Finally, in the absence of active pyrimidine synthesis by either pathway,

5 DgcQ is active at reduced efficiency, and it is likely completely turned off if, in addition to

6 UTP, also intracellular GTP (the substrate for DgcQ) concentrations drop below a given

7 threshold. Thus, dependence of full DgcQ activity on UTP would allow modulation of

8 cellulose production as soon as intracellular concentrations of this nucleotide decrease. It can

9 also be expected that low UTP concentrations will result in a decreased intracellular pool for

10 UDP-glucose, the precursor of cellulose synthesis, thus directly affecting the efficiency of the

11 bacterial cellulose synthase complex. Arresting cellulose synthesis would save energy, and

12 might possibly represent an initial step in promoting biofilm dispersal and release of

13 planktonic motile cells in response to starvation. Indeed, cellulose turnover and biofilm

14 dispersal can be increased by starvation in a manner dependent on intracellular c-di-GMP

15 concentration (Gjermansen et al., 2010).

16 In vitro DGC activity assays indicate that $\mathrm{N}$-carbamoyl-aspartate can inhibit the DgcQ

17 protein at a millimolar concentration range. Although a precise estimation of intracellular N-

18 carbamoyl-aspartate concentrations is not available, it is likely that normal intracellular

19 concentrations for this molecule are lower, even in E. coli cells actively synthesizing

20 pyrimidines. However, direct protein-protein interaction between DgcQ and enzymatically

21 active PyrB (Table 1, Figure 2) would locally increase N-carbamoyl-aspartate concentrations

22 available to the DgcQ protein. This notion would be consistent with the mode of action of

23 other DGC proteins, whose activity is often linked to specific protein-protein interaction

24 (Lindenberg et al., 2013; Rybtke et al., 2015). Future experiments will also address how c-di-

25 GMP synthesis by DgcQ might in turn affect its interaction with PyrB and, possibly, with 
1 other proteins found in co-purification experiments. From our results, it could be envisaged

2 that, as long as the de novo pyrimidine biosynthetic pathway is active, DgcQ activity, and thus

3 cellulose production, cannot be fully active. However, concentrations of exogenous uracil in

4 the order of $0.25 \mathrm{mM}$ can repress expression of the pyrBI operon (Figure S1B), likely

5 preventing PyrB production and its interaction with DgcQ (Figure S1B, Table 1, File S1).

6 Consistent with feedback control of de novo pyrimidine synthesis, growth in media

7 supplemented with $0.25 \mathrm{mM}$ uracil results in a 2-fold increase in cellulose production in $E$.

8 coli MG1655 (Figure 1D), and this effect is further amplified in mutants unable to synthesize

9 N-carbamoyl-aspartate (Garavaglia et al., 2012). Our observations suggest that DgcQ

10 allosteric control by both UTP and N-carbamoyl-aspartate allows efficient induction of

11 cellulose production in response to presence of exogenous uracil in the environment, well

12 below millimolar concentrations. The regulatory network connecting pyrimidine biosynthesis,

13 DgcQ activity, and cellulose production is shown in Figure 5.

14 Cellulose protects E. coli from harsh environmental conditions such as desiccation

15 (White et al., 2006; Gualdi et al., 2008) and its production is part of the general stress

16 response controlled by the rpoS gene (Weber et al., 2006). Thus, it can appear

17 counterintuitive that it is also induced in response to pyrimidine availability; however, it can

18 be argued that an increase in the availability of exogenous nucleotides and nitrogenous bases

19 might also follow stressful events such as extensive lysis of neighbouring cells, for instance

20 due to phage infections. Likewise, it is possible that pyrimidine and purine salvage pathways

21 might be activated by extensive DNA/RNA degradation, again following environmental

22 insults. We have not investigated whether intermediates of the de novo purine synthesis can

23 also trigger cellulose production either in a DgcQ-dependent or independent way. However, it

24 is remarkable that, in Pseudomonas aeruginosa, mutations in the pyrimidine, but not in the

25 purine biosynthetic pathway, affect biofilm formation (Ueda et al., 2009). Likewise, addition 
1 of exogenous uracil, but not adenine, results in fluorescence of Calcofluor-supplemented

2 plates in adherent-invasive Escherichia coli (Figure 1C), suggesting a specific effect of

3 pyrimidines on cellulose production. Interestingly, uracil can be found at sub-millimolar

4 concentrations in the gastro-intestinal tract of both invertebrates and mammals (Vogel-Scheel

5 et al., 2010; Lee et al., 2013), mostly as a product of the gut microbiota. Bacterial-produced

6 uracil is a strong inducer of mucosal immunity and of generation of reactive oxygen species

7 in Drosophila (Lee et al., 2013). As cellulose also plays an important role as a defense

8 mechanism against oxidative stress in Enterobacteria (White et al., 2006), it is conceivable

9 that the link between exogenous uracil sensing and cellulose production via the DgcQ protein

10 might have evolved as a preemptive defense mechanism against the host immune system.

11 Similarly, a recent work reported that, in Salmonella Typhimurium, cellulose production is

12 triggered by exogenous arginine via the DgcQ-homologue STM1987 (Mills et al., 2015):

13 thus, it might be tempting to speculate that relaying cellulose production to the availability of

14 exogenous metabolites is a widespread mechanism in Enterobacteria.

15 These results, and also our observations that the pyrimidine-sensing DgcQ protein 16 might also interact with proteins not involved in cellulose production, such as for instance 17 tRNA modification enzymes (Table 1), expand previous observations showing that 18 pyrimidine biosynthesis is hardwired to important processes such as biofilm formation, 19 virulence factor production, antimicrobial resistance, and even evolutionary strategies (Haugo 20 and Watnick, 2002; Beaumont et al., 2009; Ueda et al., 2009; Guo et al., 2016), thus 21 suggesting that pyrimidine biosynthesis flow can represent a pivotal sensing mechanism in 22 bacteria.

\section{Materials and Methods}


2 Strains and growth media, phenotypic assays and cellulose determination. Strains used in

3 this work are listed in Table S1. For strain construction and routine manipulation, bacteria

4 were grown in LB medium (10 g/l tryptone, $5 \mathrm{~g} / 1$ yeast extract, $5 \mathrm{~g} / 1 \mathrm{NaCl})$ or LB-agar

5 medium (LB medium with $15 \mathrm{~g} / \mathrm{L}$ agar). When necessary, antibiotics were added to the

6 growth medium at the following concentrations: ampicillin, $100 \mu \mathrm{g} / \mathrm{ml}$; chloramphenicol, 50

$7 \mu \mathrm{g} / \mathrm{ml}$; kanamycin, $50 \mu \mathrm{g} / \mathrm{ml}$.

8 For all other experiments, bacteria were grown either in 1:4 diluted LB medium (LB1/4) or on

9 LB1/4-agar medium (LB1/4 medium with $15 \mathrm{~g} / \mathrm{L}$ agar). LB1/4 medium was used since it

10 favors biofilm formation and adhesion factor production compared to the full strength LB

11 (Perrin et al., 2009), while retaining its complexity and supporting growth of the $\triangle$ carB and

$12 \triangle \operatorname{pyr} B$ mutants, auxotroph for pyrimidines (data not shown). If not otherwise stated

13 experiments were performed at $30^{\circ} \mathrm{C}$. Uracil was dissolved in $50 \%$ dimethyl sulfoxide

14 (DMSO) to a $10 \mathrm{mM}$ concentration and supplemented at a $0.25 \mathrm{mM}$ final concentration.

15 DMSO at a $1.25 \%$ final concentration was always added to control cultures. Congo red- (CR)

16 and calcofluor (CF)-binding phenotypic assays were essentially carried out as previously

17 described (Garavaglia et al., 2012), spotting selected overnight cultures on LB1/4-agar media

18 containing uracil, supplemented with either $0.004 \%$ Congo red and $0.002 \%$ Coomassie blue

19 (CR-medium) or $0.005 \%$ Calcofluor (CF-medium) after autoclaving. Bacteria were grown for

$2024 \mathrm{~h}$ at $30{ }^{\circ} \mathrm{C}$; phenotypes were better detected after a further $24-48 \mathrm{~h}$ incubation at $4{ }^{\circ} \mathrm{C}$.

21 Cellulose determination was performed as previously described (Gualdi et al., 2008)1.

22 Molecular biology techniques and gene expression analysis. Escherichia coli MG1655 and

23 BTH101 mutant derivatives were constructed through homologous recombination using the

$24 \lambda$-red technique, (Datsenko and Wanner, 2000); PCR products for mutant construction were

25 obtained using primer pairs listed in Table S2. Plasmids used in this work, listed in Table S1, 
1 were constructed by standard methods, inserting PCR fragments obtained using primers pairs

2 reported in Table S2 into vectors using restriction enzymes. The correctness of all newly

3 constructed plasmids was verified by sequencing.

4 Gene expression levels were measured through quantitative real-time qRT-PCR as described

5 previously (Garavaglia et al., 2012), using 16S RNA as reference gene. RNA was extracted

6 from cultures grown either in $\mathrm{LB} 1 / 4$ or in $\mathrm{LB} 1 / 4(\mathrm{ura})$ at $30^{\circ} \mathrm{C}$ in full aeration (constant

7 shaking at 100 r.p.m) either after overnight growth or during late exponential phase $\left(\mathrm{OD}_{600}=\right.$

8 0.8). The complete list of primers used for amplification is reported in Table S2.

9 DgcQ cytoplasmic domain (DgcQ cyt $_{\text {) }}$ expression and purification. E. coli BL21(DE3) strain harboring the pQE80L- $d g c Q_{\text {cyt }}$ was grown in LB medium at $37{ }^{\circ} \mathrm{C}$ under shaking 11 condition $(120 \mathrm{rpm})$, until cultures reached cellular density corresponding to $\mathrm{OD}_{600}=0.6$. The 12 temperature was lowered to $18{ }^{\circ} \mathrm{C}$, shaking increased to $150 \mathrm{rpm}$, and $6 x$ His-tagged protein 13 expression was induced adding $0.5 \mathrm{mM}$ isopropyl $\beta$-D-thiogalactopyranoside (IPTG). After $1416 \mathrm{~h}$ of growth, cells were harvested by centrifugation at $7,000 \mathrm{rpm}$ for $15 \mathrm{~min}$ at $4{ }^{\circ} \mathrm{C}$, 15 resuspended in 1/50 vol. of cold Buffer A (50 mM Tris-Cl, $\mathrm{pH} 8.0,300 \mathrm{mM} \mathrm{NaCl}, 20 \mathrm{mM}$ 16 imidazole), supplemented with $100 \mu \mathrm{g} / \mathrm{ml}$ lysozyme, $1 \mathrm{mM}$ 4-(2-Aminoethyl) benzenesulfonyl fluoride hydrochloride (AEBSF) and $100 \mu 1$ of Protease Inhibitor (P8849, SigmaAldrich) and incubated for $30 \mathrm{~min}$ on ice. After cell lysis by sonication (10 cycles of $10 \mathrm{~s}$ bursts with 30 s pauses between them), cell debris and non-soluble proteins were removed by centrifugation at $18,000 \mathrm{rpm}$ at $4{ }^{\circ} \mathrm{C}$ for $1 \mathrm{~h}$. The supernatant, containing the soluble protein

21 fraction, was loaded on a gravity chromatography column containing $1 \mathrm{~mL}$ of TALON® 22 metal affinity resin (Clontech), equilibrated with 5 volumes of cold Buffer A. To avoid non23 specific interactions, the resin was washed with 10 volumes of cold Buffer A supplemented 24 with $1 \mathrm{mM}$ AEBSF, followed by 10 volumes of 90\% Buffer A + 10\% Buffer B (50 mM Tris$25 \mathrm{Cl}, \mathrm{pH} 8.0,300 \mathrm{mM} \mathrm{NaCl}, 500 \mathrm{mM}$ imidazole). Proteins were eluted on a single step using 5 
1 volumes of $50 \%$ Buffer A $+50 \%$ Buffer B. Imidazole was immediately removed by multiple

2 PD-100 Desalting columns (GE Healthcare Life Sciences), followed by wash and elution in

3 Storage Buffer (50 mM Tris-Cl, pH 8.0, $300 \mathrm{mM} \mathrm{NaCl}, 1 \mathrm{mM}$ DTT, 5\% glycerol). If

4 required, AEBSF was added to a final concentration of $1 \mathrm{mM}$. Purified $\mathrm{DgcQ}_{\text {cyt }}$ protein in

5 Storage Buffer was used within $24 \mathrm{~h}$ for biochemical assays, as the proteins precipitated over

6 longer times.

7 DgcQ $_{\text {cyt }}$ co-purification (pull down) experiments. DgcQ $\mathrm{Q}_{\text {cyt }}$ was expressed and loaded by 8 gravity on a chromatography column containing metal affinity resin as described in the 9 previous section. After the first wash with 10 volumes of cold Buffer A, the $\mathrm{DgcQ}_{\text {cyt }}$-carrying 10 column was loaded with $5 \mathrm{~mL}$ of cleared cellular lysate deriving from cultures of MG1655 11 strain grown for $16 \mathrm{~h}$ either in presence or absence of $0.25 \mathrm{mM}$ uracil. The column was then 12 washed with 10 volumes of cold Buffer A, followed by 5 vol. of $90 \%$ Buffer A $+10 \%$ Buffer 13 B. Finally, $\operatorname{DgcQ}_{\mathrm{cyt}}$ and co-eluting proteins were eluted using 5 volumes of $50 \%$ Buffer A + $1450 \%$ Buffer B. An aliquot of the recovered protein's complexes were treated with RapiGest 15 SF (Waters), digested with trypsin and identified through MudPIT (Multidimensional Protein 16 Identification Technology) analysis, as previously described (Longo et al., 2016). In order to 17 identify specific proteins co-eluting with $6 x$ His-tagged $\mathrm{DgcQ}_{\mathrm{cyt}}$ in presence or absence of 0.25 $18 \mathrm{mM}$ uracil, outputs were analyzed with the in-house software MAProMa (multidimensional 19 algorithm protein map) (Mauri and Dehò, 2008). Different protein amounts were estimated by 20 means of the DAve (differential average) algorithm of MAProMa (Mauri, 2005). A DAve 21 value higher than 10 (or lower than -10) indicates that a given protein is present in different 22 amounts in the samples analyzed; a DAve value of either 200 or -200 indicates that a protein 23 is exclusively present in one sample.

24 Bacterial two-hybrid (BACTH) assays. For the Bacterial Adenylate Cyclase Two-Hybrid 25 System (BACTH), proteins of interest were fused to T25 and T18 fragments of B. pertussis 
1 adenylate cyclase in vectors pKT25 and pUT18, respectively, and the BACTH assay was

2 performed essentially as previously described (Longo et al., 2016). Briefly, pKT25 and 3 pUT18 plasmids derivatives (see Table S2) were used to co-transform in various 4 combinations the E. coli BTH101 or its isogenic $\triangle \operatorname{carB}$ and $\triangle p y r B$ mutants. Resulting 5 transformants were cultured in LB medium and spotted on either LB-agar medium containing $6100 \mu \mathrm{g} / \mathrm{ml}$ ampicillin, $50 \mu \mathrm{g} / \mathrm{ml}$ kanamycin, $40 \mu \mathrm{g} / \mathrm{ml}$ 5-bromo-4-chloro-3-indolyl-ß-D7 galactopyranoside (X-gal) and $0.5 \mathrm{mM}$ IPTG. Interactions between different hybrid proteins 8 were visualized after $48 \mathrm{~h}$ of incubation at $30^{\circ} \mathrm{C}$. For a quantitative measurement of protein9 protein interactions, $\beta$-galactosidase activity was measured on $100 \mu 1$ of the same LB cultures grown for $16 \mathrm{~h}$ at $30^{\circ} \mathrm{C}$ by standard Miller Assay (Miller, 1972).

11 Biochemical assays. Thermal denaturation temperature shift assays were essentially 12 performed as previously described (Cossu et al., 2010). DgcQ cyt $_{2}(20 \mu \mathrm{M})$, was mixed with 3.5 $13 \mu \mathrm{l}$ of Sypro orange (Sigma) diluted 60 -fold, $50 \mathrm{mM}$ Tris-Cl, $\mathrm{pH} 7.5$, and either ATP, or UTP, 14 or uracil, or $\mathrm{N}$-carbamoyl-aspartate, at different concentrations. Ligands were all prepared 15 fresh in $50 \mathrm{mM}$ Tris-Cl, $\mathrm{pH} 7.5$ at a stock concentration of $25 \mathrm{mM}$. Tris-Cl, $\mathrm{pH} 7.5$ was used 16 in place of ligands in negative controls. The assay was carried out using a MiniOpticon Real 17 Time PCR Detection System (Bio-Rad), designed originally for PCR; sample plates were 18 heated from $4{ }^{\circ} \mathrm{C}$ to $99{ }^{\circ} \mathrm{C}$ at a heating rate of $0.2{ }^{\circ} \mathrm{C} / 5 \mathrm{~s}$. The fluorescence emission intensity 19 was measured over the 540-700 nm wavelength range by excitation at $470-505 \mathrm{~nm}$. For 20 analysis and visualization purposes, output melting curves were manually inspected, then 21 normalized, smoothed and fitted with a 4-parameters logistic function using a custom python 22 script in order to calculate the melting temperature $\left(T_{m}\right)$.

23 Diguanylate cyclase (DGC) activity of $\mathrm{DgcQ}_{\mathrm{cyt}}$ was measured following the in vitro 24 production of the reaction product c-di-GMP at $30{ }^{\circ} \mathrm{C}$ using reverse-phase HPLC. Briefly, 25 freshly purified $\operatorname{DgcQ}_{\text {cyt }}(20 \mu \mathrm{M})$ in Storage Buffer was added to a reaction solution 
1 containing $10 \mathrm{mM} \mathrm{MnCl}_{2}, 200 \mathrm{mM} \mathrm{NaCl}, 50 \mathrm{mM}$ Tris, $\mathrm{pH}$ 7.5. After an incubation time of 5

$2 \min$ at $30{ }^{\circ} \mathrm{C}, 0.5 \mathrm{mM} \mathrm{GTP}$ was added to start the reaction. Aliquots were taken at different

3 time points between 0 and $3 \mathrm{~h}$, showing that c-di-GMP synthesis was linear during at least the

4 first $2 \mathrm{~h}$ of reaction; thus, a $2 \mathrm{~h}$-incubation time was chosen for the DGC assays in the

5 presence of various ligands. The reaction mixture was separated on reverse-phase $12.5 \mathrm{~cm}$

6 Supelcosil LC-18-DB, $3 \mu \mathrm{m}$ particle size, column using a methanol-phosphate gradient

7 (Buffer A: $100 \mathrm{mM}$ potassium phosphate buffer, pH 6.0; Buffer B: Buffer A containing 20\%

8 methanol) as previously described (Antoniani et al., 2010). Reaction products were identified

9 by comparison to standard nucleotides GTP (Fermentas) and synthetic c-di-GMP (Biolog,

10 Bremen, Germany). To test the effects of different ligands on DgcQ ${ }_{\text {cyt }}$ activity, ATP, UTP,

11 uracil, $N$-carbamoyl-aspartate, and combinations of them, were added, at different

12 concentrations to in vitro reaction mixtures and then incubated for $5 \mathrm{~min}$ at $30^{\circ} \mathrm{C}$, after which

13 the reaction was started by addition of the substrate GTP, as before. All ligands were freshly

14 prepared in $50 \mathrm{mM}$ Tris-Cl, $\mathrm{pH} 7.5$, at stock concentration of $25 \mathrm{mM}$ and used within $1 \mathrm{~h}$.

15

16

17

\section{Acknowledgments}

We would like to thank Chiara Speroni for performing $\operatorname{dgc} Q$ and $p y r B$ expression experiments. Elio Rossi was supported by a post-doctoral Fellowship from Fondazione Fratelli Confalonieri.

\section{References}

Antoniani, D., Bocci, P., Maciag, A., Raffaelli, N., and Landini, P. (2010) Monitoring of 
1 diguanylate cyclase activity and of cyclic-di-GMP biosynthesis by whole-cell assays 2 suitable for high-throughput screening of biofilm inhibitors. Applied microbiology and 3 biotechnology 85: 1095-1104.

4 Antoniani, D., Rossi, E., Rinaldo, S., Bocci, P., Lolicato, M., Paiardini, A., et al. (2013) The 5 immunosuppressive drug azathioprine inhibits biosynthesis of the bacterial signal molecule cyclic-di-GMP by interfering with intracellular nucleotide pool availability. Applied microbiology and biotechnology 97: 7325-7336.

Beaumont, H.J.E., Gallie, J., Kost, C., Ferguson, G.C., and Rainey, P.B. (2009) Experimental evolution of bet hedging. Nature 462: 90-93.

Boehm, A., Kaiser, M., Li, H., Spangler, C., Kasper, C.A., Ackermann, M., et al. (2010) Second messenger-mediated adjustment of bacterial swimming velocity. Cell 141: 107116.

Bokranz, W., Wang, X., Tschäpe, H., and Römling, U. (2005) Expression of cellulose and curli fimbriae by Escherichia coli isolated from the gastrointestinal tract. Journal of Medical Microbiology 54: 1171-1182.

Cossu, F., Malvezzi, F., Canevari, G., Mastrangelo, E., Lecis, D., Delia, D., et al. (2010) Recognition of Smac-mimetic compounds by the BIR domain of cIAP1. Protein Sci. 19: $2418-2429$.

Da Re, S. and Ghigo, J.-M. (2006) A CsgD-independent pathway for cellulose production and biofilm formation in Escherichia coli. Journal of Bacteriology 188: 3073-3087.

Datsenko, K.A. and Wanner, B.L. (2000) One-step inactivation of chromosomal genes in Escherichia coli K-12 using PCR products. Proc Natl Acad Sci USA 97: 6640-6645.

De, N., Navarro, M.V.A.S., Raghavan, R.V., and Sondermann, H. (2009) Determinants for the activation and autoinhibition of the diguanylate cyclase response regulator WspR. $J$. Mol. Biol. 393: 619-633. 
1 Eisenreich, W. and Heuner, K. (2016) The life stage-specific pathometabolism of Legionella 2 pneumophila. FEBS Lett.

3 Falconi, M., Colonna, B., Prosseda, G., Micheli, G., and Gualerzi, C.O. (1998)

4 Thermoregulation of Shigella and Escherichia coli EIEC pathogenicity. A temperature-

5 dependent structural transition of DNA modulates accessibility of virF promoter to

6 transcriptional repressor H-NS. EMBO J. 17: 7033-7043.

7 Fleming, E. and Camilli, A. (2016) ManLMN is a glucose transporter and central metabolic

Gjermansen, M., Nilsson, M., Yang, L., and Tolker-Nielsen, T. (2010) Characterization of starvation-induced dispersion in Pseudomonas putida biofilms: genetic elements and molecular mechanisms. Mol. Microbiol. 75: 815-826.

Gu, D., Guo, M., Yang, M., Zhang, Y., Zhou, X., and Wang, Q. (2016) A бE-mediated temperature gauge controls a switch from LuxR-mediated virulence gene expression to thermal stress adaptation in Vibrio alginolyticus. PLoS Pathog. 12: e1005645.

Gualdi, L., Tagliabue, L., Bertagnoli, S., Ieranò, T., De Castro, C., and Landini, P. (2008) Cellulose modulates biofilm formation by counteracting curli-mediated colonization of solid surfaces in Escherichia coli. Microbiology 154: 2017-2024.

Guo, Q., Wei, Y., Xia, B., Jin, Y., Liu, C., Pan, X., et al. (2016) Identification of a small molecule that simultaneously suppresses virulence and antibiotic resistance of Pseudomonas aeruginosa. Scientific reports 6: 19141.

Haugo, A.J. and Watnick, P.I. (2002) Vibrio cholerae CytR is a repressor of biofilm development. Mol. Microbiol. 45: 471-483. 
1 Hickman, J.W. and Harwood, C.S. (2008) Identification of FleQ from Pseudomonas 2 aeruginosa as a c-di-GMP-responsive transcription factor. Mol. Microbiol. 69: 376-389.

3 Irie, Y., Borlee, B.R., O'Connor, J.R., Hill, P.J., Harwood, C.S., Wozniak, D.J., and Parsek, 4 M.R. (2012) Self-produced exopolysaccharide is a signal that stimulates biofilm 5 formation in Pseudomonas aeruginosa. Proc. Natl. Acad. Sci. U.S.A. 109: 20632-20636.

6 Karimova, G., Pidoux, J., Ullmann, A., and Ladant, D. (1998) A bacterial two-hybrid system 7

9 Lee, K.-A., Kim, S.-H., Kim, E.-K., Ha, E.-M., You, H., Kim, B., et al. (2013) Bacterial10 derived uracil as a modulator of mucosal immunity and gut-microbe homeostasis in Drosophila. Cell 153: 797-811.

Lindenberg, S., Klauck, G., Pesavento, C., Klauck, E., and Hengge, R. (2013) The EAL domain protein YciR acts as a trigger enzyme in a c-di-GMP signalling cascade in E. coli biofilm control. EMBO J. 32: 2001-2014.

Llamas, M.A., Imperi, F., Visca, P., and Lamont, I.L. (2014) Cell-surface signaling in Pseudomonas: stress responses, iron transport, and pathogenicity. FEMS Microbiol. Rev. 38: $569-597$.

Longo, F., Motta, S., Mauri, P., Landini, P., and Rossi, E. (2016) Interplay of the modified nucleotide phosphoadenosine 5'-phosphosulfate (PAPS) with global regulatory proteins in Escherichia coli: modulation of cyclic AMP (cAMP)-dependent gene expression and interaction with the HupA regulatory protein. Chem. Biol. Interact.

Mauri, P. (2005) Identification of proteins released by pancreatic cancer cells by multidimensional protein identification technology: a strategy for identification of novel cancer markers. The FASEB Journal.

Mauri, P. and Dehò, G. (2008) A proteomic approach to the analysis of RNA degradosome 
composition in Escherichia coli. Meth. Enzymol. 447: 99-117.

2 Miller, J. (1980) The lacI gene: its role in lac operon control and its use as a genetic system.

$3 \quad$ Cold Spring Harbor Monograph Archive 07:.

4 Miller, J.H. (1972) Experiments in molecular genetics Cold Spring Harbor Laboratory.

5 Mills, E., Petersen, E., Kulasekara, B.R., and Miller, S.I. (2015) A direct screen for c-di-GMP

Monteiro, C., Saxena, I., Wang, X., Kader, A., Bokranz, W., Simm, R., et al. (2009)

9 Characterization of cellulose production in Escherichia coli Nissle 1917 and its biological consequences. Environ. Microbiol. 11: 1105-1116.

Perrin, C., Briandet, R., Jubelin, G., Lejeune, P., Mandrand-Berthelot, M.-A., Rodrigue, A., and Dorel, C. (2009) Nickel promotes biofilm formation by Escherichia coli K-12 strains that produce curli. Appl. Environ. Microbiol. 75: 1723-1733.

Purcell, E.B. and Tamayo, R. (2016) Cyclic diguanylate signaling in Gram-positive bacteria. FEMS Microbiol. Rev. 40: 753-773.

Righetti, F., Nuss, A.M., Twittenhoff, C., Beele, S., Urban, K., Will, S., et al. (2016) Temperature-responsive in vitro RNA structurome of Yersinia pseudotuberculosis. Proc. Natl. Acad. Sci. U.S.A. 113: 7237-7242.

Rossi, E., Longo, F., Barbagallo, M., Peano, C., Consolandi, C., Pietrelli, A., et al. (2016) Glucose availability enhances lipopolysaccharide production and immunogenicity in the opportunistic pathogen Acinetobacter baumannii. Future Microbiology fmb.15.153-15.

Römling, U., Galperin, M.Y., and Gomelsky, M. (2013) Cyclic di-GMP: the first 25 years of a universal bacterial second messenger. Microbiol. Mol. Biol. Rev. 77: 1-52.

Römling, U., Gomelsky, M., and Galperin, M.Y. (2005) C-di-GMP: the dawning of a novel bacterial signalling system. Mol. Microbiol. 57: 629-639. 
1 Rybtke, M., Berthelsen, J., Yang, L., Høiby, N., Givskov, M., and Tolker-Nielsen, T. (2015)

2 The LapG protein plays a role in Pseudomonas aeruginosa biofilm formation by 3 controlling the presence of the CdrA adhesin on the cell surface. MicrobiologyOpen 4: $4 \quad 917-930$.

5 Schirmer, T. (2016) C-di-GMP Synthesis: Structural Aspects of Evolution, Catalysis and $6 \quad$ Regulation. J. Mol. Biol. 428: 3683-3701.

7 Serra, D.O., Richter, A.M., and Hengge, R. (2013) Cellulose as an architectural element in 8 spatially structured Escherichia coli biofilms. Journal of Bacteriology 195: 5540-5554.

Simm, R., Morr, M., Kader, A., Nimtz, M., and Römling, U. (2004) GGDEF and EAL domains inversely regulate cyclic di-GMP levels and transition from sessility to motility. Mol. Microbiol. 53: 1123-1134.

Skarstad, K. and Katayama, T. (2013) Regulating DNA replication in bacteria. Cold Spring Harb Perspect Biol 5: a012922-a012922.

Turnbough, C.L. and Switzer, R.L. (2008) Regulation of pyrimidine biosynthetic gene expression in bacteria: repression without repressors. Microbiol. Mol. Biol. Rev. 72: 266$300-$ table of contents.

Ueda, A., Attila, C., Whiteley, M., and Wood, T.K. (2009) Uracil influences quorum sensing and biofilm formation in Pseudomonas aeruginosa and fluorouracil is an antagonist. Microb Biotechnol 2: 62-74.

Vasil, M.L. and Ochsner, U.A. (1999) The response of Pseudomonas aeruginosa to iron: genetics, biochemistry and virulence. Mol. Microbiol. 34: 399-413.

Vogel-Scheel, J., Alpert, C., Engst, W., Loh, G., and Blaut, M. (2010) Requirement of purine and pyrimidine synthesis for colonization of the mouse intestine by Escherichia coli. Appl. Environ. Microbiol. 76: 5181-5187.

Weber, H., Pesavento, C., Possling, A., Tischendorf, G., and Hengge, R. (2006) Cyclic-di- 
GMP-mediated signalling within the sigma network of Escherichia coli. Mol. Microbiol.

2

62: 1014-1034.

White, A.P., Gibson, D.L., Kim, W., Kay, W.W., and Surette, M.G. (2006) Thin aggregative fimbriae and cellulose enhance long-term survival and persistence of Salmonella. Journal of Bacteriology 188: 3219-3227.

Wu, K., Xu, H., Zheng, Y., Wang, L., Zhang, X., and Yin, Y. (2016) CpsR, a GntR family regulator, transcriptionally regulates capsular polysaccharide biosynthesis and governs bacterial virulence in Streptococcus pneumoniae. Scientific reports 6: 29255.

Zogaj, X., Nimtz, M., Rohde, M., Bokranz, W., and Römling, U. (2001) The multicellular morphotypes of Salmonella typhimurium and Escherichia coli produce cellulose as the second component of the extracellular matrix. Mol. Microbiol. 39: 1452-1463.

\section{Figure legends}

Figure 1. Link between pyrimidine biosynthesis and cellulose production in E. coli MG1655.

(A) Schematic representation of de novo (light blue background) and salvage (light brown background) pathways for pyrimidine biosynthesis in Escherichia coli. The metabolic intermediate $\mathrm{N}$-carbamoyl-aspartate and the nitrogenous base uracil, which belongs respectively to the de novo and salvage pathways for pyrimidine biosynthesis are highlighted in green and orange. Shared reaction between the two pathways are highlighted in a purple background. Solid lines represent a single reaction driven by an enzymatic complex encoded by genes indicated on the right. Dashed lines represent multiple consecutive reactions carried out by the products of the genes listed on the right. (B) Phenotypes of E. coli MG1655 and its mutant derivatives affected in pyrimidine biosynthesis or cellulose production on LB1/4 medium added with Congo red (CR) with or without $0.25 \mathrm{mM}$ uracil. Infographic below the 
1 picture summarises the ability of each strain to synthesize the metabolic intermediate $\mathrm{N}$ -

2 carbamoyl-L-aspartate (NcAsp) (green=able; grey=unable). (C) Upper panels: Phenotypes on

3 LB1/4 medium added with the fluorescent dye Calcofluor (CF) with or without $0.25 \mathrm{mM}$

4 uracil. In the absence of added uracil, no strain showed any detectable fluorescence; $E$.coli

5 MG1655 is shown as a representative of the CF-negative phenotype. Lower panel: CF

6 phenotype of adherent-invasive E. coli (AIEC) strain LF82 with or without the addition of

7 uracil (ura) and adenine (ADE). For both CR and CF phenotype experiments, bacterial strains

8 were grown at $30^{\circ} \mathrm{C}$ for 24 hours and plates were incubated at $4{ }^{\circ} \mathrm{C}$ for at least 48 hours to

9 enhance CR and CF binding. (D) Determination of cellulose in LB1/4 medium with or

10 without supplementation with $0.25 \mathrm{mM}$ uracil.

12 Figure 2. DgcQ diguanylate cyclase and its interaction with components of the aspartate 13 transcarbamylase enzyme. (A) Schematic representation of the DgcQ protein and its 14 artificially expressed shorter variants $6 \mathrm{xHis}-\mathrm{DgcQ}_{\mathrm{cyt}}$ and $\mathrm{T} 18-\mathrm{DgcQ}$ cyt comprising only the 15 cytoplasmic domain of the protein fused with a histidine tag and the T18 subunit of 16 Bordetella pertussis adenylate cyclase, respectively. (B) Bacterial Adenylate Cyclase Two17 Hybrid (BACTH) assays on X-gal-supplemented plates. E. coli BTH101 wild-type (WT) 18 strain, and its isogenic derivatives mutated in either the $\operatorname{car} B$ or $p y r B$ genes, were transformed 19 with a combination of two-hybrid vector plasmids (pKT25, T25; pUT18, T18), allowing 20 expression of the indicated proteins. Only relevant combinations are presented (for the full set 21 of interactions refer to Panel $\mathrm{C}$ of this figure). Blue colour is indicative of a reconstituted 22 adenylate cyclase activity, i.e., of protein-protein interaction. Strains harbouring pUT18 and 23 pKT25 empty vectors are considered as negative control, while strain co-expressing the T2524 Zip and T18-Zip fusion proteins represents the positive control. The infographic on the right 25 highlight the ability of each strain to synthesize carbamoyl-phosphate (carbamoyl-P in the 
1 Figure), the precursor of $N$-carbamoyl-aspartate. (C) Full set of protein interactions and their

2 strength in BACTH assay measured as B-galactosidase activity on overnight cultures grown in

3 LB medium at $30^{\circ} \mathrm{C}$. Results obtained in either the BTH101 strain or its $\triangle p y r B$ mutant, both

4 proficient for the synthesis of $N$-carbamoyl-aspartate precursor, carbamoyl-phosphate, are

5 highlighted by a green background; a grey background highlights results in the $\triangle$ carB mutant,

6 unable to synthesize carbamoyl-phosphate. Single experiments are represented by dots, and a

7 minimum of three independent replicate is reported. Standard deviations are shown.

9 Figure 3. $\mathrm{DgcQ}_{\mathrm{cyt}}$ thermal denaturation temperature shift assays. In the presence of a ligand, a shift in the melting curve can be appreciated. The difference in $50 \%$ melting temperature $11\left(\Delta \mathrm{T}_{\mathrm{m}}\right.$, reported in the table $)$ is calculated at the temperature in which $50 \%$ of total 12 fluorescence is observed. Curves and $\Delta \mathrm{T}_{\mathrm{m}}$ reported in the table are the average of three 13 independent measurements. Standard deviations for $\Delta \mathrm{T}_{\mathrm{m}}$ are shown.

15 Figure 4. In vitro diguanylate cyclase (DGC) activity of the purified $\mathrm{DgcQ}_{\text {cyt }}$ protein. c-di16 GMP production was measured through high-pressure liquid chromatography (HPLC) analysis. For each sample, purified $\mathrm{DgcQ}_{\text {cyt }}(20 \mu \mathrm{M})$ was incubated for 5 minutes at $30^{\circ} \mathrm{C}$ in the reaction buffer (see Materials and Methods) supplemented, when necessary, with either $0.1 \mathrm{mM}$ UTP or $2.5 \mathrm{mM} \mathrm{N}$-carbamyl-aspartate $(N \mathrm{cAsp})$. The reaction was started by adding the substrate GTP $(0.5 \mathrm{mM})$ and run for 2 hours at $30^{\circ} \mathrm{C}$. c-di-GMP levels (ca. $\left.0.8 \mu \mathrm{M}\right)$ of the

21 control reaction containing GTP only was set to 1, and relative amounts are shown. Results 22 are mean \pm standard errors of the mean of three independent experiments. The asterisks denote significant differences $(* \mathrm{p} \leq 0.05 ; * * \mathrm{p} \leq 0.01$ Holm-Š́ídák multigroup analysis). 
1 Figure 5. Schematic representation of the possible molecular network connecting pyrimidine

2 biosynthesis, DgcQ activity, and cellulose production. Dashed lines indicate missing reactions

3 if connecting metabolic intermediates. Green lines indicate a positive effect on the activity of

4 the protein, while red lines indicate a negative one. IM: inner membrane; OM: outer

5 membrane; PG: peptidoglycan; UDP-Glu: UDP-glucose.

6

7

8 Supplementary Figure S1. Relative expression of the (A) yedQ and (B) pyrB genes

9 determined using Real-Time RT-PCR on RNA extracted from cultures in late exponential

10 (Late exp., $\mathrm{OD}_{600}=0.8$ ) and stationary (Stat., 24h of growth) phase. 16S RNA transcript was

11 used as reference gene. $\Delta \mathrm{Ct}$ values between the genes of interest and $16 \mathrm{~S}$ RNA were set at 1.0

12 for MG1655 in Late exponential phase in LB1/4 medium without addition of uracil.

13 Transcript levels in other growth conditions are expressed as relative values. Experiments

14 were repeated at least three times, each time in duplicate; standard deviations are shown.

15 
Table 1. Proteins co-eluted with $\mathrm{DgcQ}_{\mathrm{cyt}}$ in pull-down experiments.

\begin{tabular}{|c|c|c|c|c|c|}
\hline \multirow{2}{*}{$\begin{array}{l}\text { Accession } \\
\mathrm{n} .^{\circ}\end{array}$} & \multirow{2}{*}{$\begin{array}{l}\text { Protein } \\
\text { name }\end{array}$} & \multirow{2}{*}{ Description } & \multicolumn{2}{|c|}{ Score ${ }^{a}$} & \multirow[t]{2}{*}{ DAve $^{b}$} \\
\hline & & & - & uracil & \\
\hline$N P \_417225.1$ & TruD & $\begin{array}{l}\text { tRNA(Glu) pseudouridine(13) } \\
\text { synthase }\end{array}$ & 0 & 40.21 & 200 \\
\hline$N P \_415404.1$ & $\operatorname{Inf} A$ & translation initiation factor IF-1 & 0 & 34.28 & 200 \\
\hline NP_418400.1 & $\operatorname{TrmA}$ & $\begin{array}{l}\text { tRNA m(5)U54 methyltransferase, } \\
\text { SAM-dependent }\end{array}$ & 0 & 30.24 & 200 \\
\hline NP_417659.1 & MlaC & $\begin{array}{l}\text { ABC transporter maintaining } \mathrm{OM} \\
\text { lipid asymmetry, periplasmic binding } \\
\text { protein }\end{array}$ & 36.26 & 0 & -200 \\
\hline$N P \_416470.1$ & Dcm & DNA cytosine methyltransferase & 35.24 & 0 & -200 \\
\hline NP 418666.1 & $\underline{\text { PyrB }}$ & $\begin{array}{l}\text { aspartate carbamoyltransferase, } \\
\text { catalytic subunit }\end{array}$ & $\underline{40.3}$ & $\underline{0}$ & $\underline{-200}$ \\
\hline NP 418665.1 & $\underline{\text { Pyrl }}$ & $\begin{array}{l}\text { aspartate carbamoyltransferase, } \\
\text { regulatory subunit }\end{array}$ & $\underline{40.31}$ & $\underline{0}$ & $\underline{-200}$ \\
\hline
\end{tabular}

Cell extracts were from E. coli grown in LB1/4 medium (-) or LB1/4 medium supplemented with $0.25 \mathrm{mM}$ uracil (uracil)

Score and DAve are both algorithms of the MAProMa software (42).

a Score is a function of the number of uniquely identified peptides in each sample.

${ }^{b}$ DAve provides a relative amount ratio between the two samples. Values of $\geq 1$ or $\leq-1$ indicate different relative protein amounts between two samples (positive values: higher amount in extracts from cells grown in LB1/4 +0.25mM uracil; negative values: higher amount in extracts from cells grown in LB1/4 with no uracil supplementation); a DAve value of either 200 or -200 indicates that a given protein is exclusively present in either sample (with or without uracil, respectively).

PyrB and Pyrl, the catalytic and regulatory subunits of aspartate carbamoyltransferase, are underlined. 
A

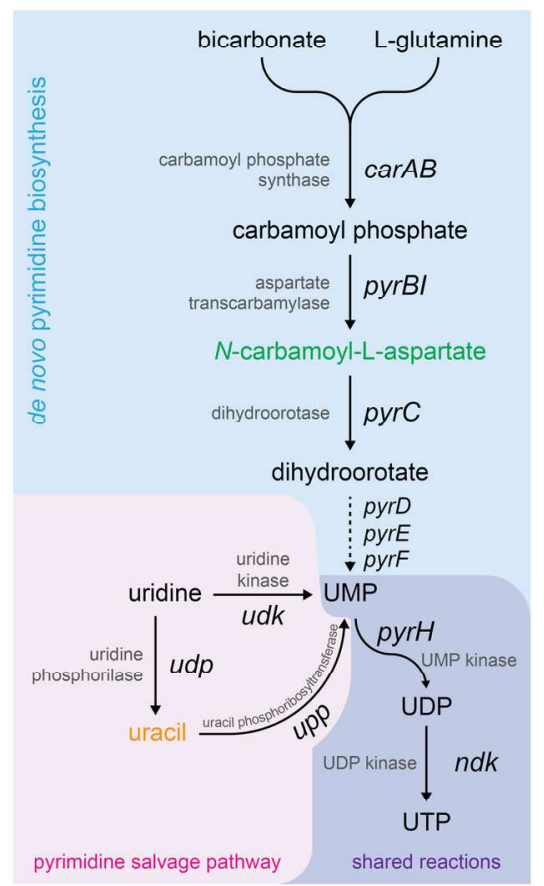

B

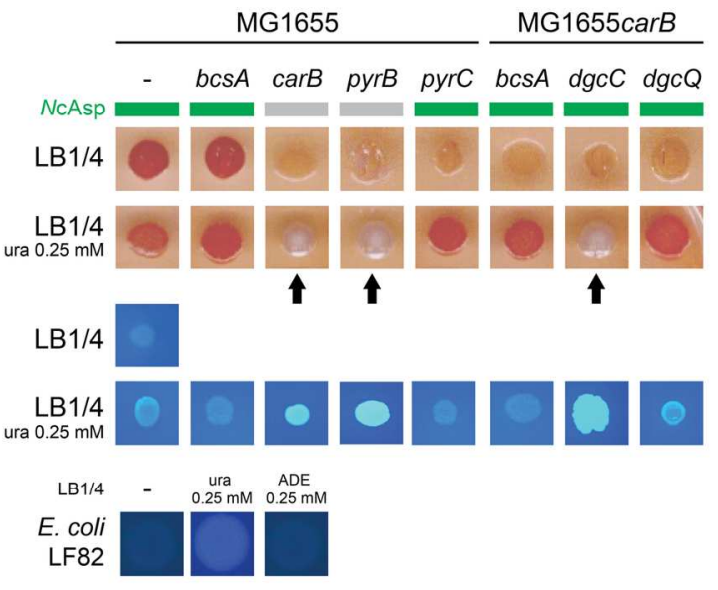

D

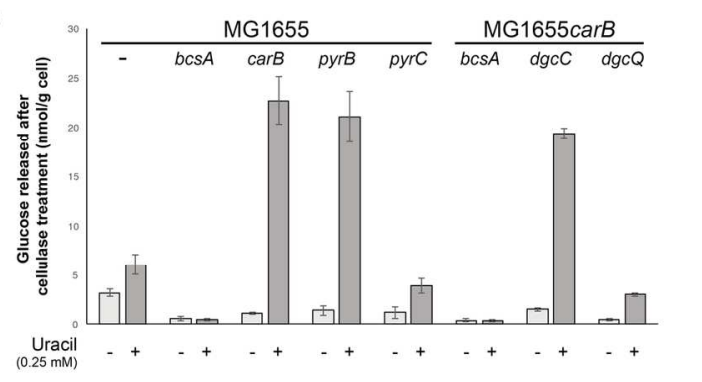

Figure 1

$157 \times 121 \mathrm{~mm}(300 \times 300 \mathrm{DPI})$ 


\section{Page 33 of 36}

A

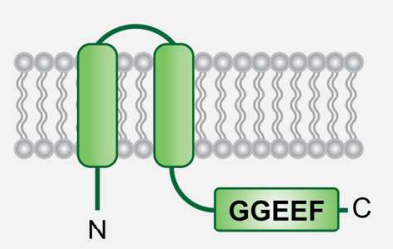

periplasmic cytoplasmic

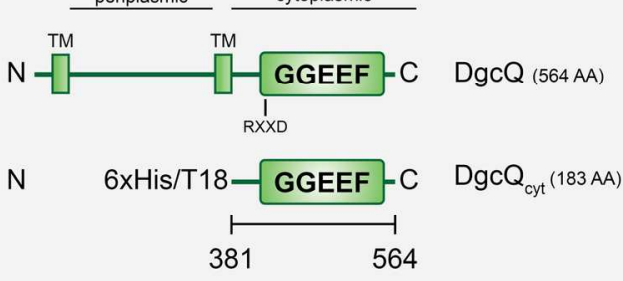

c

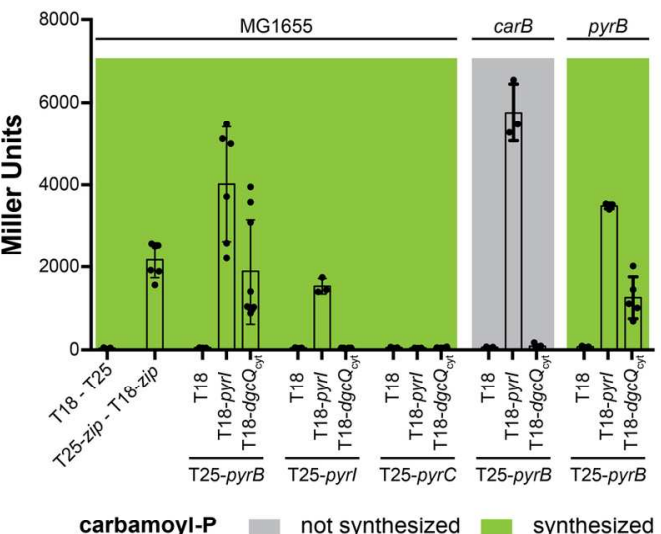

B

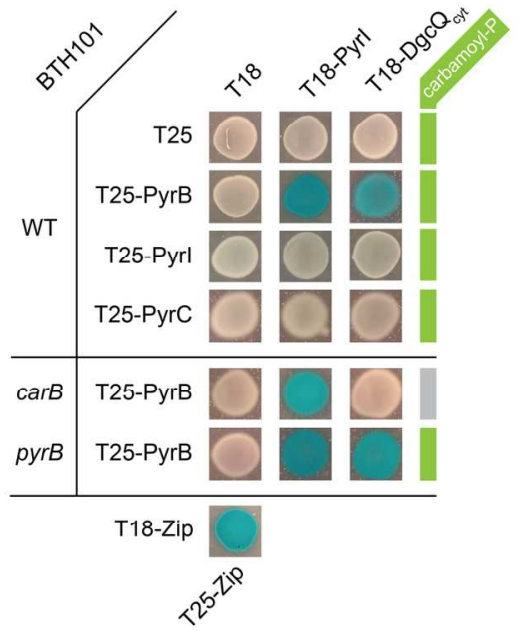



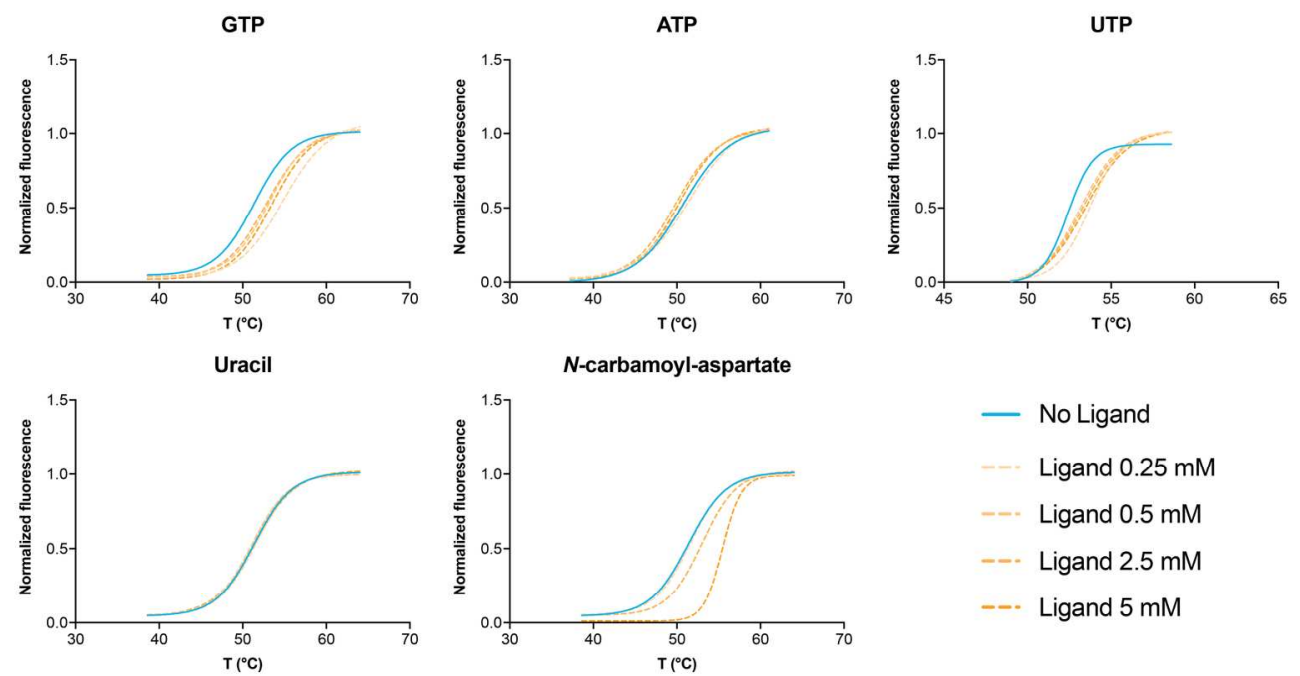

\begin{tabular}{|r|cccc|}
\multicolumn{4}{c}{$\Delta \mathrm{T}_{\mathrm{m}}\left(\mathrm{T}_{\mathrm{m} \text { (ligand) }}-\mathrm{T}_{\mathrm{m} \text { (noligand) }}\right)$} \\
\cline { 2 - 5 } \multicolumn{1}{c|}{} & $0.25 \mathrm{mM}$ & $0.5 \mathrm{mM}$ & $2.5 \mathrm{mM}$ & $5 \mathrm{mM}$ \\
\hline GTP & $3.6 \pm 1.1$ & $1.8 \pm 0.1$ & $1.4 \pm 0.1$ & $2.1 \pm 0.4$ \\
ATP & $-0.5 \pm 0.1$ & $-0.6 \pm 0.3$ & $0.1 \pm 0.4$ & $0.7 \pm 0.4$ \\
UTP & $1.3 \pm 0.5$ & $1.1 \pm 0.1$ & $1.2 \pm 0.6$ & $1.2 \pm 0.3$ \\
Uracil & $0.0 \pm 0.2$ & $-0.5 \pm 0.1$ & $-0.4 \pm 0.4$ & $-0.1 \pm 0.4$ \\
N-carbamoyl-aspartate & $0.1 \pm 0.1$ & $0.0 \pm 0.1$ & $1.5 \pm 0.1$ & $3.9 \pm 0.3$ \\
\hline
\end{tabular}

Figure 3

$172 \times 149 \mathrm{~mm}(300 \times 300$ DPI $)$ 


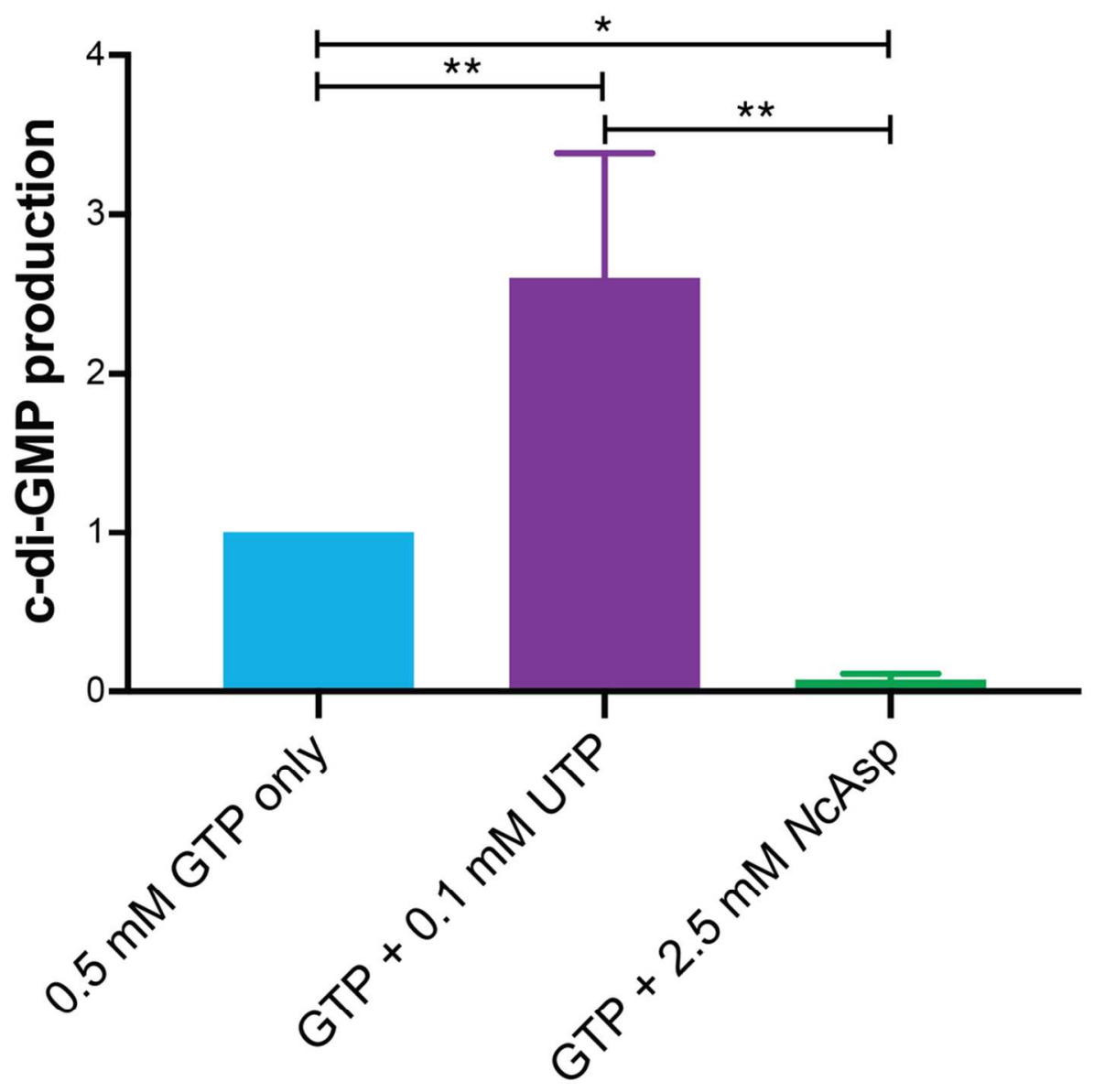

Figure 4

$95 \times 95 \mathrm{~mm}(300 \times 300 \mathrm{DPI})$ 


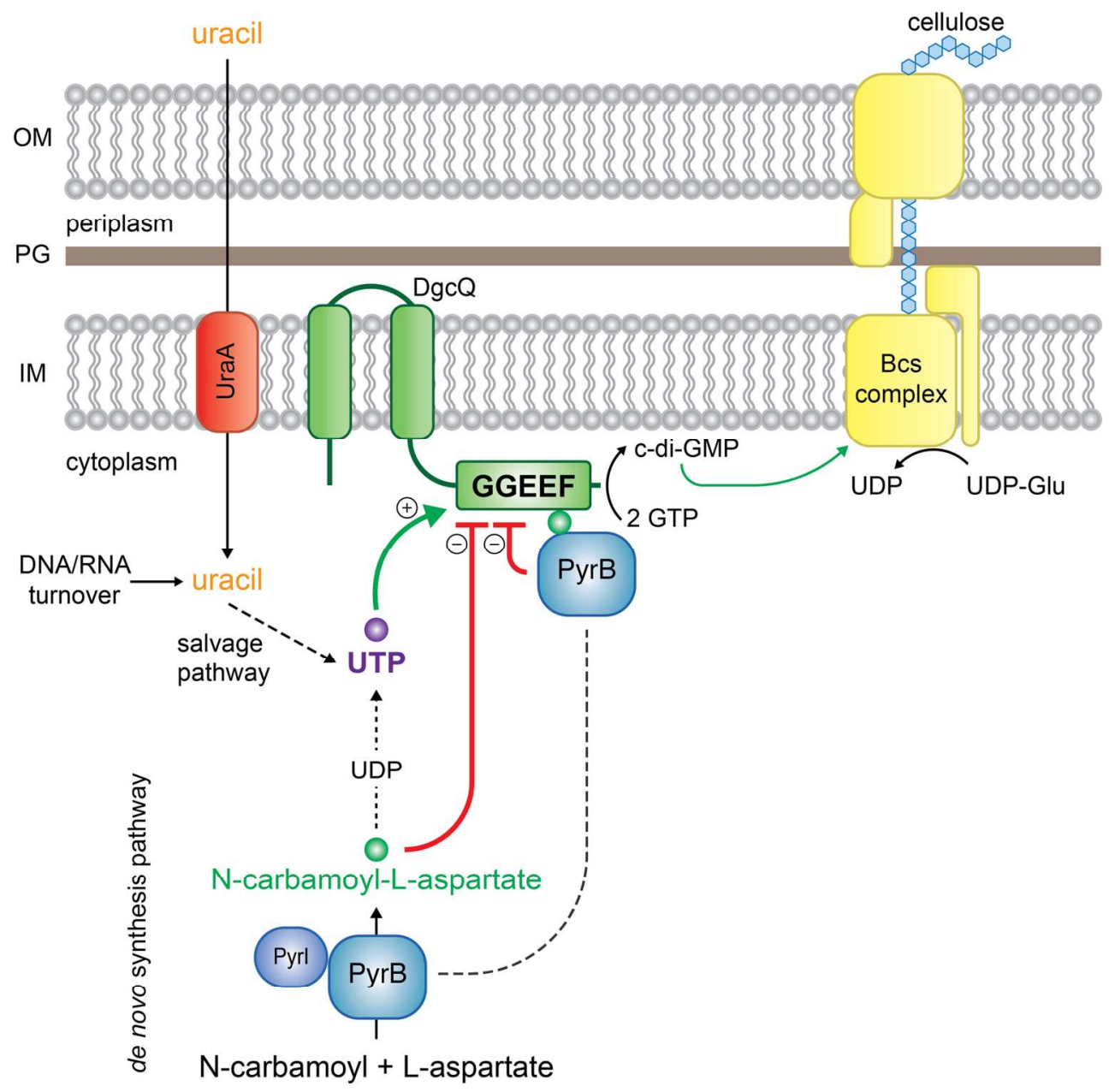

Figure 5

$154 \times 152 \mathrm{~mm}(300 \times 300$ DPI $)$ 